Bulletin of Electrical Engineering and Informatics

Vol. 11, No. 1, February 2022, pp. 68 81

ISSN: 2302-9285, DOI: 10.11591/eei.v11i1.3460

\title{
Development of regional load management system based on rural, semi urban and urban loads-a critical analysis
}

\author{
Ayandeep Ganguly ${ }^{1}$, Arindam Kumar Sil ${ }^{2}$ \\ ${ }^{1}$ Department of Electrical Engineering, Haldia Institute of Technology, West Bengal, India \\ ${ }^{2}$ Department of Electrical Engineering, Jadavpur University, West Bengal, India
}

\begin{tabular}{ll}
\hline \hline Article Info & ABSTRACT \\
\cline { 2 - 3 } Article history: & $\begin{array}{l}\text { The sharp rise in population during the last half century has created immense } \\
\text { pressure on the resources required for generation of energy essential to lead } \\
\text { a comfortable and healthy lifestyle. The drive towards } 100 \% \text { electrification } \\
\text { in developing countries like India has also contributed to this increase in } \\
\text { Revised Nov 13, } 2021\end{array}$ \\
Accepted Dec 17, 2021 & $\begin{array}{l}\text { Now, the world is moving more and more towards renewable energy. This } \\
\text { paper presents a model where several regions are combined together based } \\
\text { on the demand profile of the regions segregated as urban, semi urban and } \\
\text { rural along with the flexibility to schedule loads on the basis of availability } \\
\text { of renewable energy sources within the area of the regions. The main focus } \\
\text { is on detailed neural-networking based load forecasting and developing a } \\
\text { load management system to manage load based on availability of distributed } \\
\text { generation capacity and available tariff system. A solution is proposed in } \\
\text { this paper based on a new approach to answer load management on the basis } \\
\text { of region, population demographics and per capita energy consumption. A } \\
\text { Form factor }\end{array}$ \\
$\begin{array}{l}\text { Fuzzy logic } \\
\text { considerable amount of improvement to manage demand is intended to be } \\
\text { attained and has been demonstrated in this research work. }\end{array}$ \\
$\begin{array}{l}\text { Power management } \\
\text { Renewable }\end{array}$
\end{tabular}

This is an open access article under the CC BY-SA license.

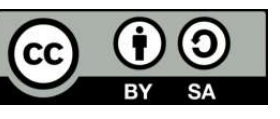

Corresponding Author:

Ayandeep Ganguly

Department of Electrical Engineering, Haldia Institute of Technology

721657, West Bengal, India

Email: gangulyayandeep@hithaldia.in

\section{INTRODUCTION}

The electricity demand is predicted to increase substantially in the future. The major contributors would be the rising population, improvement in lifestyle, rural electrification and growing demand for air conditioning and digital devices in the semi-urban and urban areas. The growth of electricity demand is projected to be $2.1 \%$ per year globally, of which a major portion will be contributed by the developing countries. The increased generation to meet the demand will result in higher $\mathrm{CO}_{2}$ emissions and faster depletion of fossil fuels. These factors combined with the sustainable development goals are pushing renewable energy to the forefront, playing a major role in meeting the electricity demand growth [1], [2]. In such a scenario, the proper utilisation of the available resources and providing efficient service to the consumers can be done by effective load management systems [3]. Load management approach can either be targeted towards supply side management or demand side management as explored by Deka et al. [4] and Tan et al. [5]. Compared to the supply side management, demand side management has been a more explored area. The simplest approach towards demand side management considers the objective of peak load and consumer cost reduction proposed by Teive [6] but it is not the most efficient as it does not consider the integration of renewable sources or appliance usage pattern of consumers thus reducing consumer comfort. The application of computational intelligence is finding increased application in many fields [7]-[11]. It has 
also gained immense importance in developing load forecasting and management techniques [12]-[15]. Different techinues have been applied to propose solutions for unit commitment problem, improvement of stability and reactive power compensation [16]-[18]. However, though some of these techniques consider consumer comfort [19] but none of them consider the difficulty of applying the solution to a large consumer base. The area under a utility which is expected to implement these solutions is bound to have huge variations in the behaviour and lifestyle pattern of the consumers. This leads to a difference in the appliance concentration and usage pattern. The division of the supply area into rural, semi urban and urban regions can provide a better framework for determining the parameters needed to design aggregate models of different consumer categories. Integration of renewable sources, battery storage, electric vehicles and the involvement of the consumers in the demand side management makes the system more efficient [20]-[22]. Artificial intelligence integrated techniques have demonstrated good efficiency in reducing demand and cost [23], [24]. An approach to mitigate the problems occurring from increased renewable penetration in the domestic sector has been proposed by Gong et al. [25]. The scheduling flexibility of different type of loads are required to be considered to move towards the goal of efficient operation of integrated systems [26]. However, these proposed solutions are designed for particular consumer categories. They do not explore the challenges that would be faced while applying these solutions to different consumer categories with variation in usage pattern. Also, based upon the region where the solution needs to be applied, the same consumer class may have different electricity usage behaviour. This difference may also render the solution inefficient for widespread application. Thus, a framework needs to be developed for the identification of the type of region and the consumer category preferably from the load consumption pattern. Based on the output of this framework, the required modifications can be made to the parameters of the solution to increase its efficiency for different consumer bases. Rural electrical demand and growth trends are explored by Oluwasii et al. [27]. Equivalent models of loads with flexible schedules would make the systems more robust and require less computational resources for operation making demand side management easier [28], [29]. While such models can be efficiently implemented in urban areas, the demand side management of rural areas may require a different approach of processing data [30]. With increase in distributed generation systems there has been a rise of clusters of consumers and generator units. The active participation of such units can be facilitated through aggregators and virtual power players [31]. The design of energy storage units, generation unit commitment and scheduling solutions for such systems have been an area of vigorous research lately [32], [33]. Performance analysis of such systems under islanded conditions is also of great importance. Improved communication is key to the efficient operation of such systems. IoT and cloud computing can be used to develop an efficient communication system [34]. Increased penetration of electric vehicles in the conventional system has given rise to the need of optimal voltage control of the distribution system and efficient power management of an electric vehicle [35], [36]. However, the approach towards developing a load management system based on regional classification of loads is yet to be taken. There have been several approaches towards integration of renewable energy sources in the demand response strategies. But, the concept of regional renewable energy resource development strategy based on the characteristics and growth prediction of regional loads is still unexplored.

Thus, the objective of this work is to develop a load management system based on diversification of load on a regional basis. The regional loads have been proposed to be categorized as urban, semi urban and rural based on per capita energy consumption, population growth and load profile. Along with this, to develop a flexible and robust load management system based on the subcategories, renewable energy integration becomes inevitable. The proposed regional load management system model is based on the following approach:

- A fuzzy logic tool-based approach is used to develop region wise load profiles of different categories of consumers.

- The real time load data is correlated with the developed load profiles to classify the region from which the data is obtained as urban, semi urban and rural.

- The loads to be supplied per hour are classified into two categories-one which can be supplied by renewable and the other which has to be supplied form grid.

- The proposed model can be further used to predict the supply growth requirement in the future to meet the power demand based on the growth pattern of the selected loads in the concerned region.

The rest of the paper layout is as; section 2 elaborates the fuzzy inference system used to develop the regional load profiles, rescheduling strategy by particle swarm optimization (PSO) and the fuzzy tool to classify loads for being supplied from renewable or grid. Section 3 describes various performance metrices and graphical representations of the proposed technique. Section 4 summarises the main outcomes of this literature. 


\section{PROPOSED LOAD MANAGEMENT STRATEGY}

In this section we first present the load switching and rescheduling models of the regional loads and then propose a method to determine the percentage of loads that can be supplied by renewable energy. This process will contribute towards renewable energy growth planning based on the composition and growth of load demand in the regions supplied by different utilities.

\subsection{Model of switching schedule of loads}

The area supplied by each utility can be divided into three regions Urban, Semi-Urban and Rural based on the population. The loads of every region can be further subdivided into residential, commercial, industrial, agricultural and public lighting. It is understandable that each area will have different concentration of loads based on the income and lifestyle of the people and accordingly the percentage of total load as well as loads of individual category that can be supplied with the renewable energy will vary. The loads of each type again comprise of non-shift able and flexible loads. In our work we have taken Residential and commercial loads of an urban and a rural area respectively. To provide an effective model for load to renewable energy mapping first it is required to develop a switching profile of each load and a rescheduling strategy to reduce the peak load and stress on generation facilities. In order to develop a switching profile fuzzy logic has been used in this work. It has been seen that a reasonable modelling of consumption pattern can be done by computational intelligence using individual appliances as basic building blocks [37]. An upper limit on the number of appliances that can be switched on at the same time is provided by a prefixed hourly maximum power consumption value. This value has been determined by forecasting with ANN. ANN was selected for it's efficiency in multivariate forecasting [38], [39]. The fuzzy rule base of the system has been developed after extensive study of the data provided by surveys over multiple cities and towns spread over different regions [40], [41].

The number of urban residential and commercial appliance ownerships are considerably higher compared to the rural areas. The usage patterns of the appliances were used to develop the Fuzzy Rule base an example of which is shown in Table 1. The time of the day has been divided into five membership functions namely early morning (EM), morning (M), afternoon (A), evening (E), late evening (LE). Also, the priority of the appliances and their probability to be switched on has been divided into 5 membership functions namely very high $(\mathrm{VH})$, high $(\mathrm{H})$, medium $(\mathrm{M})$, low (L), very low (VL). Trapezoidal membership functions have been taken for both the input parameters whereas the output parameter has been modelled by triangular membership functions.

Table 1. Fuzzy rulebase of AC

\begin{tabular}{cccccc}
\hline \multirow{2}{*}{ Load priority } & EM & M & A & E & LE \\
\hline VH & L & M & VH & VH & L \\
H & VL & L & H & H & VL \\
M & VL & VL & M & M & VL \\
L & VL & VL & L & L & VL \\
VL & VL & VL & VL & VL & VL \\
\hline
\end{tabular}

The entire day has been divided into $\mathrm{T}$ time periods for each of which every appliance is assigned a switching value through the fuzzy logic program such as:

$$
\begin{aligned}
& S_{l, i}^{h}=a, \forall a \in[0,1] \\
& \sum_{i=1}^{h} a_{i} \neq r t_{l} \\
& \underset{\substack{i=1 \\
\sum_{l . i}-1}}{e, h}+d_{l, i}^{e, h} \leq r f_{h}^{\max } \\
& \sum_{\mathrm{l}=1}^{\mathrm{n}-1} \mathrm{~d}_{\mathrm{l}}^{\mathrm{i}}<\emptyset \\
& \mathrm{P}_{\mathrm{i}}=\mathrm{P}_{\mathrm{i}}(.) \mid \mathrm{P}_{\mathrm{i}}(\mathrm{t}) \text { subject to }(1) \text { to }(4) \\
& \text { Obj }=\left[\sum_{\mathrm{h}=1}^{24}\left(\sum_{\mathrm{l}=1}^{\mathrm{N}} \mathrm{P}_{\mathrm{l}, \mathrm{h}}-\mathrm{P}_{\mathrm{ref}, \mathrm{h}}\right)^{2}+\kappa\right] \\
& \kappa=1000 * \sqrt{\left[\mathrm{rt}_{\mathrm{l}}-\mathrm{rt}_{\mathrm{act}}\right]^{2}}
\end{aligned}
$$

Where Obj is the objective function and $\kappa$ is the penalty function incorporated into the objective function to ensure that the appliances complete their runtimes. This has been used as a soft penalty function to allow a

Bulletin of Electr Eng \& Inf, Vol. 11, No. 1, February 2022: 68-81 
small amount of flexibility in the appliance runtimes. This can be justified with the fact that $\mathrm{rt}_{1}$ is the average runtime of the $\mathrm{l}^{\text {th }}$ appliance which means some appliances belonging to the $\mathrm{l}^{\text {th }}$ set will have less runtimes than the average while some will have more. The best population among multiple runs is selected based on the Obj function value. The area and load division structure are shown in Figure 1(a) and the structure of the fuzzy system is shown in Figure 1(b).

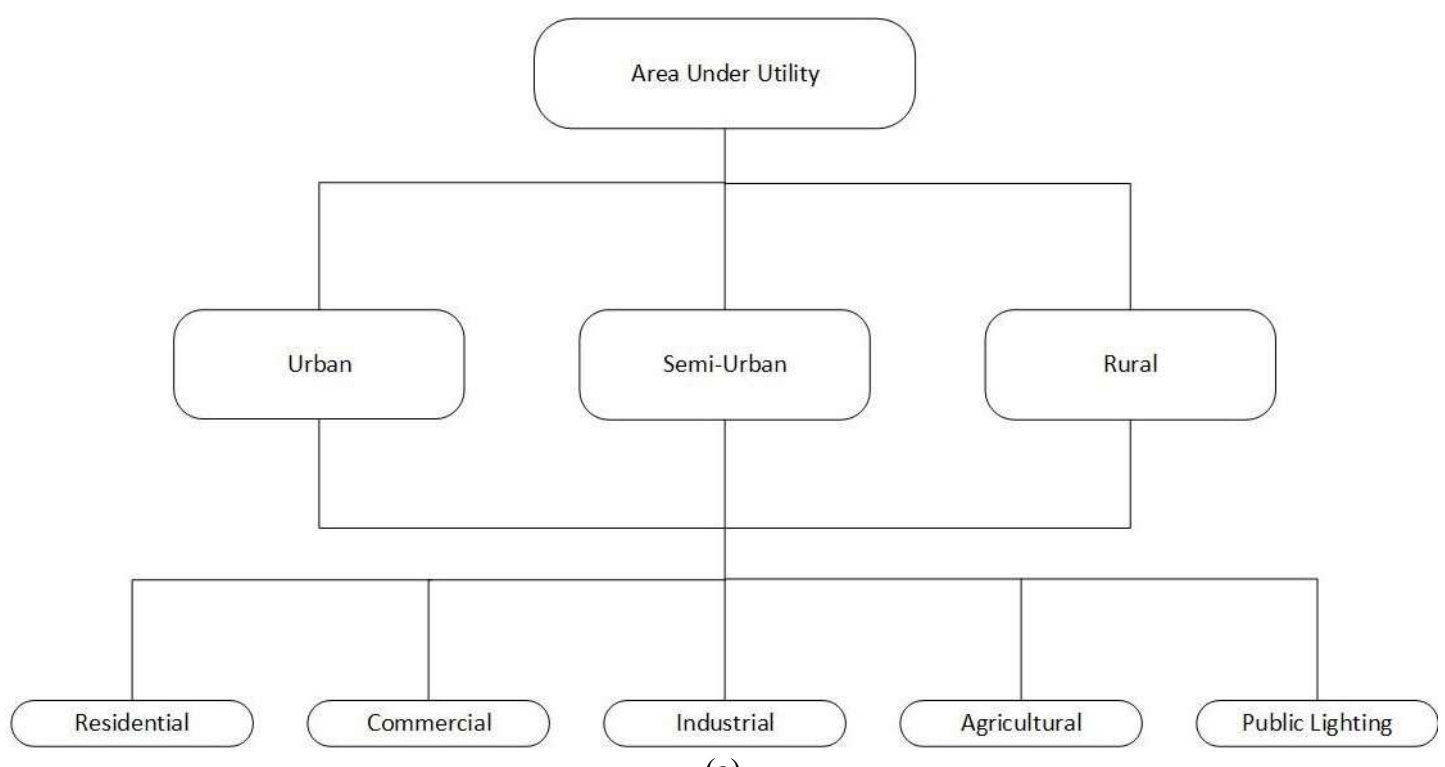

(a)

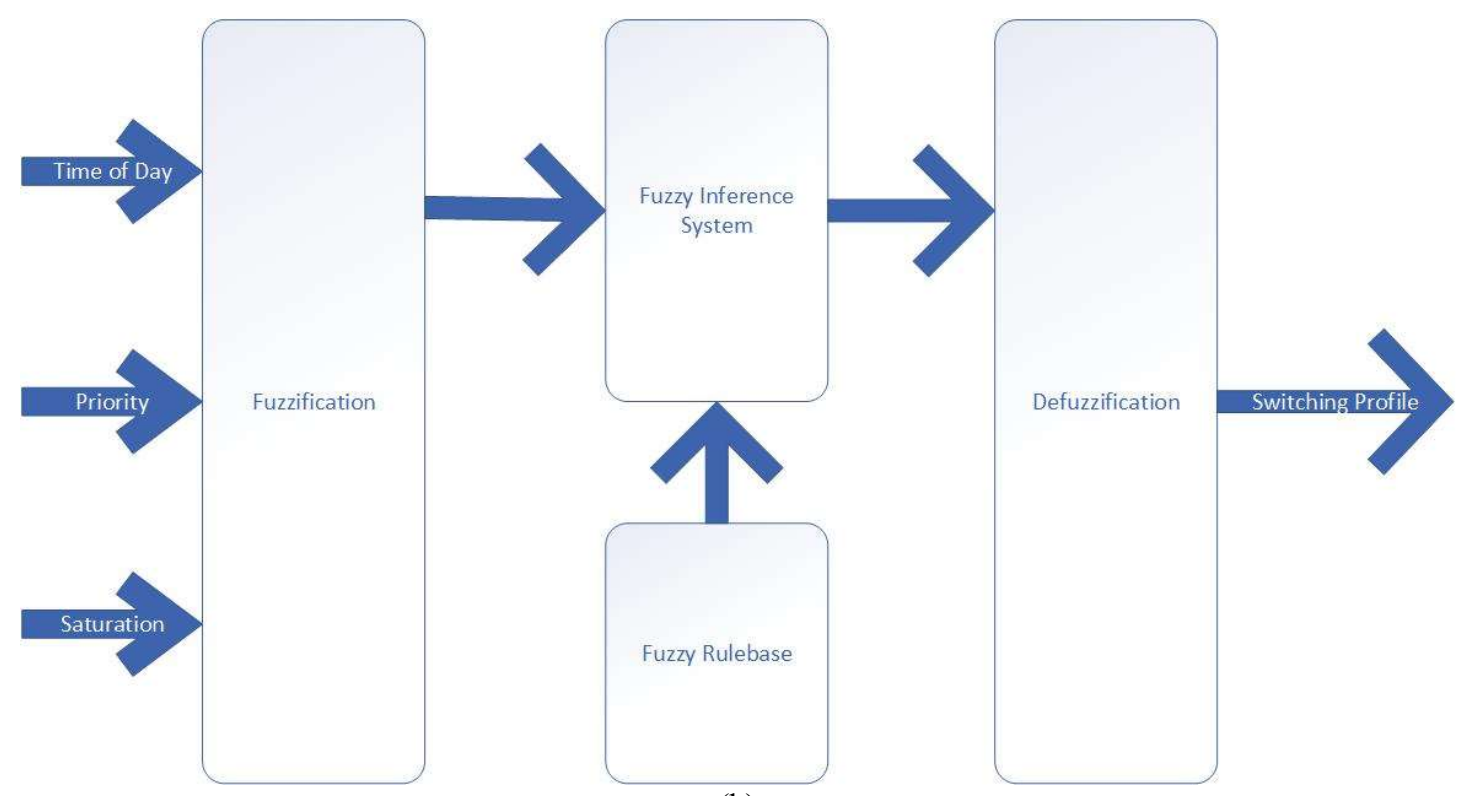

(b)

Figure 1. Structures of the area division and fuzzy logic process (a) area and load division structure and (b) fuzzy structure

\subsection{Classification of regions}

The load profiles that were developed using fuzzy logic are utilised to classify different regions based on the correlation between the output of the fuzzy logic program and the actual load demand input or the region. The synthetic load profile $\mathrm{L}_{\text {synth }}^{\mathrm{XY}}$ and the actual load demand profile $\mathrm{L}_{\text {act }}$ are first normalized using the formula:

Development of regional load management system based on rural, semi urban ... (Ayandeep Ganguly) 


$$
\begin{aligned}
& L_{\text {synth,norm }}^{X Y, h}=\frac{L_{\text {synth }}^{X Y, h}}{L_{\text {synth }}^{X, \text { max }}} \\
& \mathrm{L}_{\text {act,normh }}^{\mathrm{h}}=\frac{\mathrm{L}_{\text {act }}^{\mathrm{h}}}{\mathrm{L}_{\text {max }}^{\text {act }}} \\
& \mathrm{L}_{\text {synth }}^{\mathrm{XY} \mathrm{h}}=\sum_{\mathrm{i}=1}^{\mathrm{N}} \mathrm{L}_{\text {synth,i }}^{\mathrm{XY}, \mathrm{h}}
\end{aligned}
$$

where: $\mathrm{L}_{\text {synth,i }}^{\mathrm{XY}}=$ fuzzy logic output of $\mathrm{h}^{\text {th }}$ hour of the $\mathrm{i}^{\text {th }}$ load of $\mathrm{Y}^{\text {th }}$ type of $\mathrm{X}^{\text {th }}$ region

$\mathrm{N}=$ total number of loads of $\mathrm{Y}^{\text {th }}$ type in $\mathrm{X}^{\text {th }}$ region

$\mathrm{L}_{\text {act }}^{\max }=$ maximum value of the input load profile in time period $\mathrm{T}$

Then the correlation between them is obtained using the following formula:

$$
\begin{aligned}
& \operatorname{cor}\left(\mathrm{L}_{\text {act,norm }}, \mathrm{L}_{\text {synth,norm }}^{\mathrm{XY}}\right)=\frac{\operatorname{cov}\left(\mathrm{L}_{\text {act,norm }}, \mathrm{L}_{\text {synth,norm }}^{\mathrm{XY}}\right)}{\sigma\left(\mathrm{L}_{\text {act,norm }}\right) * \sigma\left(\mathrm{L}_{\text {synth,norm }}^{\mathrm{X}} \mathrm{Y}\right)} \\
& \mathrm{L}_{\text {act }} \in \mathrm{XYifcor}\left(\mathrm{L}_{\text {act,norm }}, \mathrm{L}_{\text {synth,norm }}^{\mathrm{XY}}\right) \geq 0.8
\end{aligned}
$$

where: $\forall \mathrm{X} \in$ [Urban, Semi Urban, Rural]

$\forall Y \in$ [Residential, Commercial, Industrial, Agricultural, PublicWorks]

\subsection{Rescheduling of loads for better load factor}

After formation of the switching profiles each appliance of $\mathrm{Y}^{\text {th }}$ type in $\mathrm{X}^{\text {th }}$ region is obtained as $\left[\mathrm{a}_{\mathrm{i}, 1}^{\mathrm{XY}}, \mathrm{a}_{\mathrm{i}, 2}^{\mathrm{XY}} \ldots ., \mathrm{a}_{\mathrm{i}, \mathrm{H}}^{\mathrm{XY}}\right] \in \mathrm{R}^{\mathrm{M} \times \mathrm{N}}$ where $\mathrm{M}=\sum_{\mathrm{i}=1}^{\mathrm{X}^{\prime}} \sum_{\mathrm{j}=1}^{\mathrm{Y}^{\prime}} \sum_{\mathrm{k}=1}^{\mathrm{A}} \mathrm{a}_{\mathrm{k}}^{\mathrm{ij}}$ and $\mathrm{N}=\mathrm{H}$ where $\mathrm{X}^{\prime}=$ total number of regions, $\mathrm{Y}^{\prime}=$ total number of consumer types and $\mathrm{A}=$ total number of appliances in under each consumer type of each region. Each appliance will have a different set of starting and stopping time $\left[\mathrm{t}_{\text {start }}, \mathrm{t}_{\text {stop }}\right] \in \mathrm{R}^{(\mathrm{M} \times \mathbb{2})}$ between which they can be rescheduled. This start and stop times have been decided by taking into consideration the different user data obtained from surveys and data repositories of utility services. PSO has been used to perform the rescheduling to minimize the objective function developed as:

$$
\text { Obj }=\min \left[\sum_{\mathrm{h}=1}^{\mathrm{H}}\left(\sum_{\mathrm{i}=1}^{\mathrm{M}} \phi_{\mathrm{i}}^{\mathrm{h}} \times \mathrm{P}_{\mathrm{i}}^{\mathrm{rt}(\mathrm{h})}-\text { avg. Load }\right)^{2}\right]
$$

Where $\mathrm{H}$ denotes the maximum time slots the day has been divided into, $\mathrm{M}$ denotes the total number of appliances under consideration defined earlier, $\phi_{\mathrm{i}}^{\mathrm{h}} \in[0,1]$ denotes the switching status of the load satisfying the following conditions:

$$
\begin{aligned}
& E_{v}-E=\frac{h}{2 \cdot m}\left(k_{x}^{2}+k_{y}^{2}\right) \\
& \phi_{\mathrm{i}}^{\mathrm{h}}=[0,1] \forall \mathrm{t} \in\left[\mathrm{t}_{\text {start }, \mathrm{i}}, \mathrm{t}_{\text {stop }, \mathrm{i}}\right] \\
& \phi_{\mathrm{i}}^{\mathrm{h}}=0 \forall \mathrm{t} \notin\left[\mathrm{t}_{\text {start } \mathrm{i}}, \mathrm{t}_{\text {stop }, \mathrm{i}}\right] \\
& \mathrm{rt}_{\mathrm{i}}^{\mathrm{XY}}=\mathrm{a}_{\mathrm{i}, \mathrm{H}}^{\mathrm{XY}}-\mathrm{a}_{\mathrm{i}, 1}^{\mathrm{XY}}
\end{aligned}
$$

$\mathrm{P}_{\mathrm{i}}^{\mathrm{rt}(\mathrm{h})}=$ the power consumption demand of ith load on the runtime slot corresponding to the $\mathrm{h}^{\text {th }}$ time slot of the day and avg. Load $=\frac{1}{\mathrm{H}} \sum_{\mathrm{i}=1}^{\mathrm{H}} \sum_{\mathrm{j}=1}^{\mathrm{M}} \mathrm{P}_{\mathrm{j}}^{\mathrm{rt}(\mathrm{i})}$. The function of the load scheduling program is to bring the load demand factor as close to 1 as possible by filling in the valleys and reducing the peaks in the daily demand curve. This serves to ensure that the load consumption is fully optimised so that when the loads are selected for renewable or grid supply there is no wastage of resources due to inefficient load consumption pattern. The demand to be supplied at each time slot can be defined by:

$$
\sum_{\mathrm{i}=1}^{\mathrm{M}} \mathrm{P}_{\mathrm{i}}^{\mathrm{rt}(\mathrm{h})}=\sum_{\mathrm{j}=1}^{\mathrm{J}} \mathrm{NSL}_{\mathrm{j}}(\mathrm{h})+\sum_{\mathrm{k}=1}^{\mathrm{K}} \mathrm{CL}_{\mathrm{k}}(\mathrm{h})-\sum_{\mathrm{l}=1}^{\mathrm{L}} \mathrm{DL}_{\mathrm{l}}(\mathrm{h}) .
$$

Where $\mathrm{NSL}_{\mathrm{j}}(\mathrm{h})=\mathrm{j}^{\text {th }}$ non-schedulable load at $\mathrm{h}^{\text {th }}$ time slot, $\mathrm{CL}_{\mathrm{k}}(\mathrm{h})=\mathrm{k}^{\text {th }}$ connected load at $\mathrm{h}^{\text {th }}$ time slot which was either already present in the time slot of concern or disconnected from another time slot and 
connected to the present time slot and $\mathrm{DL}_{\mathrm{l}}(\mathrm{h})=\mathrm{l}^{\text {th }}$ disconnected load which has been disconnected from the time slot in concern and shifted to another time slot.

\subsection{Tagging the scheduled loads to determine which loads can be supplied by renewable energy}

The loads are tagged in two parts-those which can be supplied by renewable energy and those who can be supplied by grid. The division of loads is done by using a fuzzy rule base, an example of which is given in Table 2. The renewable energy available in the region is classified into three categories: $\mathrm{H}, \mathrm{M}$ and $\mathrm{L}$.

Table 2. Fuzzy rule base for load source mapping with high renewable availability

\begin{tabular}{cccccc}
\hline \multirow{2}{*}{ Runtime } & \multicolumn{5}{c}{ Power consumption } \\
& VH & H & M & L & VL \\
\hline VH & NL & NL & NL & L & L \\
H & NL & NL & L & L & VL \\
M & NL & L & L & VL & VL \\
L & L & L & VL & VL & VL \\
VL & L & L & VL & VL & VL \\
\hline
\end{tabular}

The power consumption of each load has been classified into five categories: VH, H, M, L and VL and the time duration of continuous consumption for each load starting from the hour under consideration is divided into five categories: VH, H, M, L and VL. On every hour the different loads are tagged to be supplied by either renewable energy or directly from the grid based on the following:

$$
\begin{aligned}
& S_{i}^{X Y, h+r t}=f\left(r t_{i}^{X Y, h}, P_{i}^{X Y}, B^{R}, W_{i}^{X Y, h}\right) \\
& B^{R}=\sum_{i=1}^{N} \lambda_{i}^{X} \\
& \forall S_{i}^{X Y, h} \in[1,2]
\end{aligned}
$$

where: $S_{i}^{X Y, h+r t}=$ switch status of $i^{\text {th }}$ load of $Y^{\text {th }}$ type in the $X^{\text {th }}$ region in $(h+r t)^{\text {th }}$ hour

1 =possibility to be supplied by renewable sources

2 =supplied by grid

$\lambda_{i}^{X}=$ available power from renewable source energy of $i^{\text {th }}$ type in $X^{\text {th }}$ region

$\mathrm{N}=$ total number of renewable energy sources in the $\mathrm{Y}^{\text {th }}$ region

$\mathrm{rt}=$ runtime of $\mathrm{i}^{\text {th }}$ load of $\mathrm{Y}^{\text {th }}$ type in $\mathrm{X}^{\text {th }}$ region

$\mathrm{P}_{\mathrm{i}}^{\mathrm{XY}}=$ power rating of the $\mathrm{i}^{\text {th }}$ load of $\mathrm{Y}^{\text {th }}$ type in the $\mathrm{X}^{\text {th }}$ region

$\mathrm{W}_{\mathrm{i}}^{\mathrm{XY}, \mathrm{h}}=$ tagged status of $\mathrm{i}^{\text {th }}$ load of $\mathrm{Y}^{\text {th }}$ type in the $\mathrm{X}^{\text {th }}$ region at $\mathrm{h}^{\text {th }}$ hour

The loads that are tagged each hour for being supplied by a certain source continues to be supplied from that as source for the consecutive hours in which it is in continuous operation. While classifying the different loads at those hours the load that is already tagged due to continuous operation from a previous hour is skipped but provided with the highest priority to be provided from the supply it is already tagged with.

\subsection{Redistributing the regional loads in case of source failure}

Sometimes a source may fail to deliver in a region at any hour such that

$$
\sum_{\mathrm{i}=1}^{\mathrm{N}} \mathrm{P}(\text { act })_{\mathrm{i}}^{\mathrm{X}, \mathrm{h}}<\sum_{\mathrm{i}=1}^{\mathrm{N}} \mathrm{P}(\text { pred })_{\mathrm{i}}^{\mathrm{X}, \mathrm{h}}
$$

where: $\sum_{i=1}^{N} P(a c t){ }_{i}^{X, h}=$ actual available power from renewable sources of the $X^{\text {th }}$ region in the $h^{\text {th }}$ hour.

$\sum_{i=1}^{N} P(\text { pred })_{i}^{X, h}=$ predicted available power from renewable sources of the $X^{\text {th }}$ region in the $h^{\text {th }}$ hour. In such a case it is necessary to reorganise the loads projected to be supplied by renewable energy. The loads are redistributed according to their priority and state of operation such that

or,

$$
\mathrm{L}_{\mathrm{i}}^{\mathrm{XY}, \mathrm{h}}>\mathrm{L}_{\mathrm{j}}^{\mathrm{ZY}, \mathrm{h}_{\text {ifrt }}} \mathrm{XY}_{\mathrm{i}}^{\mathrm{X}}>0, \mathrm{rt}_{\mathrm{j}}^{\mathrm{ZY}}=0 \text { and } \mathrm{PR}_{\mathrm{i}}^{\mathrm{XY}}=\mathrm{PR}_{\mathrm{j}}^{\mathrm{ZY}, \mathrm{h}}
$$

$$
\begin{aligned}
& L_{i}^{X Y, h}>L_{j}^{Z Y, h}{ }_{i f P R}^{X Y, h}>P R_{j}^{Z Y} \\
& S_{i}^{X Y, h+r t}=1
\end{aligned}
$$




$$
\mathrm{S}_{\mathrm{j}}^{\mathrm{ZY}, \mathrm{h}+\mathrm{rt}} \in[0,2]
$$

where: $[0,1,2] \in$ [switchedoff, renewablesupplied, gridsupplied]

$\mathrm{L}_{\mathrm{i}}^{\mathrm{XY}, \mathrm{h}}=\mathrm{i}^{\text {th }}$ load of the $\mathrm{Y}^{\text {th }}$ type of $\mathrm{X}^{\text {th }}$ region in $\mathrm{h}^{\text {th }}$ hour

$\mathrm{L}_{\mathrm{i}}^{\mathrm{ZY}, \mathrm{h}}=\mathrm{i}^{\mathrm{th}}$ load of the $\mathrm{Y}^{\text {th }}$ type of $\mathrm{Z}^{\text {th }}$ region in $\mathrm{h}^{\text {th }}$ hour

$\mathrm{PR}_{\mathrm{i}}^{\mathrm{XY}, \mathrm{h}}=$ Priority of the $\mathrm{i}^{\text {th }}$ load of the $\mathrm{Y}^{\text {th }}$ type of $\mathrm{X}^{\text {th }}$ region in $\mathrm{h}^{\text {th }}$ hour

$\mathrm{PR}_{\mathrm{i}}^{\mathrm{ZY}, \mathrm{h}}=$ Priority of the $\mathrm{i}^{\text {th }}$ load of the $\mathrm{Y}^{\text {th }}$ type of $\mathrm{Z}^{\text {th }}$ region in $\mathrm{h}^{\text {th }}$ hour

$\forall \mathrm{X}, \mathrm{Z} \in$ [urban, semiurban, rural]

$\forall \mathrm{Y} \in$ [Residential, Commercial, Industrial, Agricultural, PublicWorks]

\section{RESULTS AND DISCUSSION}

Based on the mathematical discussion given in section 2 an algorithm 1 was developed to form a reference template to compare and distinguish between different regions and load categories, reschedule them to decrease the load factor and finally categorize them into the loads than can be supplied by renewable and those which need to be supplied by grid. The output of the program for providing the template for comparison is given in Figure 2. The seasonal variation of the daily load demand output for Urban residential area unit is shown in Figure 2(a) and that of Urban commercial unit area is shown in Figure 2(b).
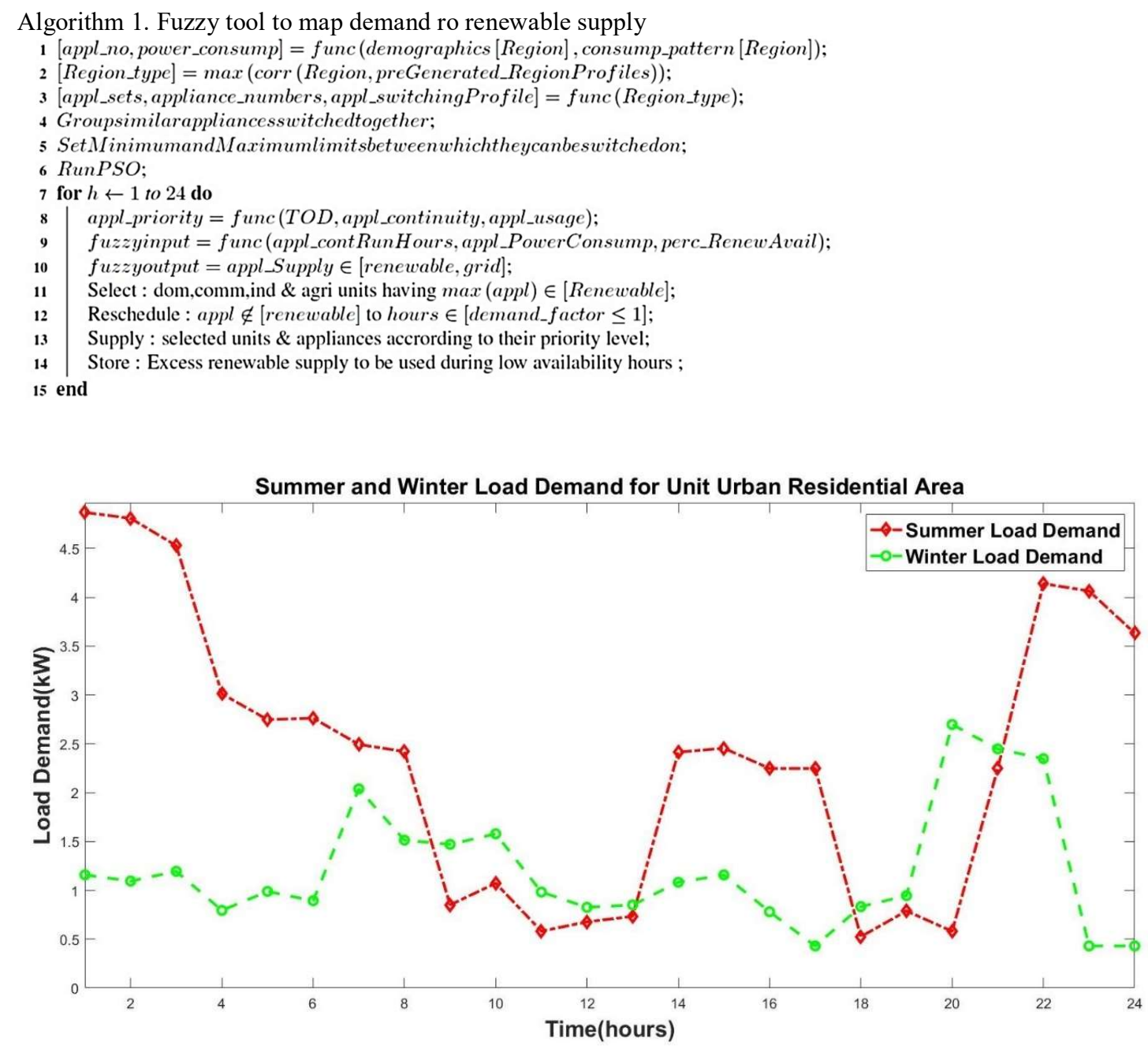

(a)

Outputs of the fuzzy logic tool (a) the output of the fuzzy tool for developing unit urban residential load demand 


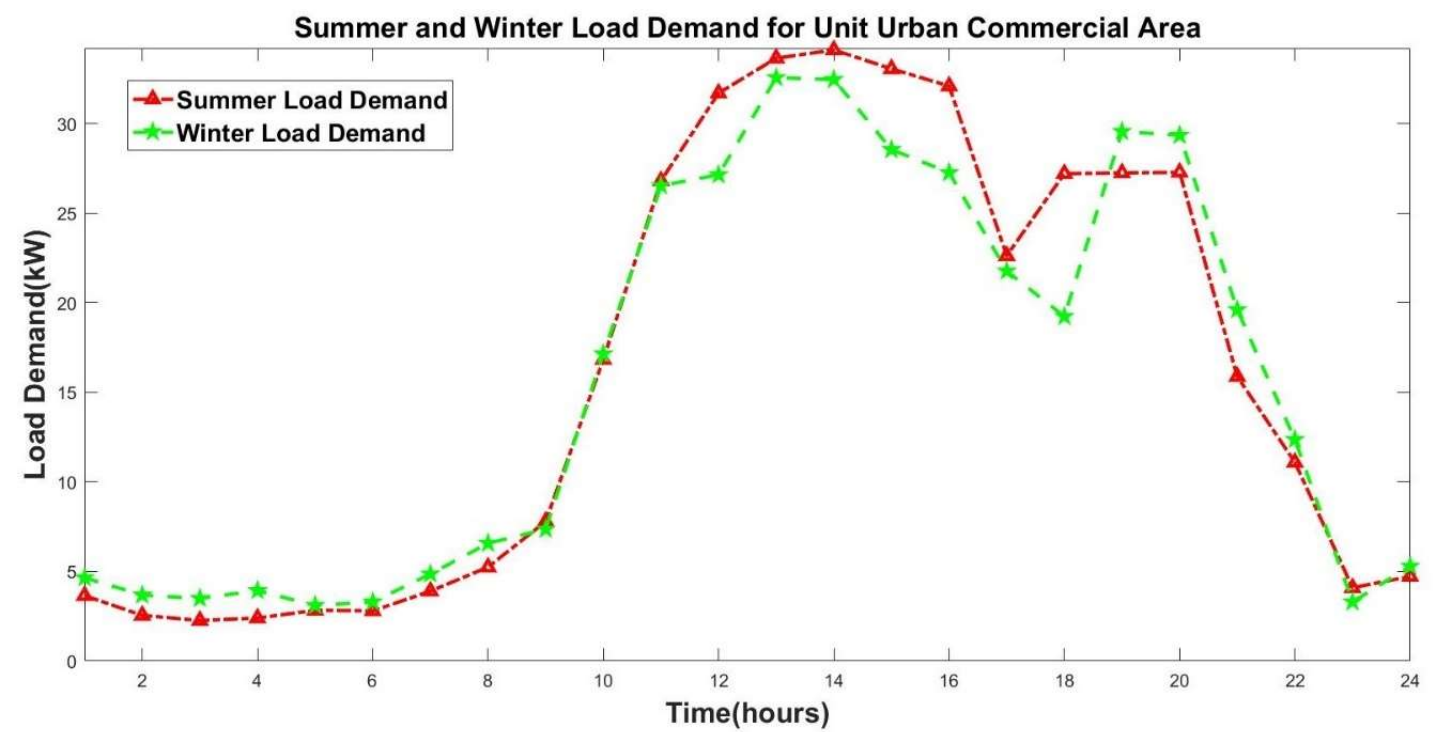

(b)

Figure 2. Outputs of the fuzzy logic tool (b) the output of the fuzzy tool for developing unit urban commercial load demand (continue)

The data obtained from the fuzzy tool whose outputs have been shown above were used to find correlation with the actual energy consumption data obtained from different surveys and utility reports [40], [41]. The output of the correlation method provided good results in identifying both the region and type of consumer based on the normalized load demand values and the load demand profile. The result of the comparison has been shown below in Table 3. The urban residential demand curve scores above 0.8 when correlated with the urban residential data provided by the fuzzy tool whereas we get much lower correlation values when the actual urban residential demand data is correlated with the other outputs of the fuzzy tool. The same result is observed for the other regional data also. Thus, it can distinctly identify the load demand profile based on the region and the consumer category.

Table 3. Correlation data

\begin{tabular}{cccc}
\hline \multirow{2}{*}{ Real time data } & \multicolumn{3}{c}{ Output data of fuzzy tool } \\
& Urban residential & Urban commercial & Rural residential \\
\hline Urban residential & 0.8414 & -0.7727 & -0.1234 \\
Urban commercial & -0.6735 & 0.8662 & 0.2341 \\
Rural residential & -0.1962 & 0.2242 & 0.8551 \\
\hline
\end{tabular}

After the region and consumer category was identified from the composite actual energy consumption data, the appliances most prevalent among the identified consumer category of the identified region type were selected from the list of appliances developed from the data obtained from online survey and physical survey. The number of these appliances were set according to the population of the region obtained from government websites and the ownership percentage of each appliance among the population. Then PSO was applied to reschedule the appliances to bring the load factor as close as possible to 1. For developing an effective rescheduling model, the loads of the different consumer categories of a region were classified into shiftable loads and non-shiftable loads. The start and stop times between which each load can be rescheduled was fixed considering the region type, consumer type and load type as these factors are very important in scheduling loads. A load of same type may have different operating schedules based on the region and the consumer who is using it. The output after scheduling the loads for combined area loads and rural residential loads is shown in Figure 3(a) and Figure 3(b) respectively. 


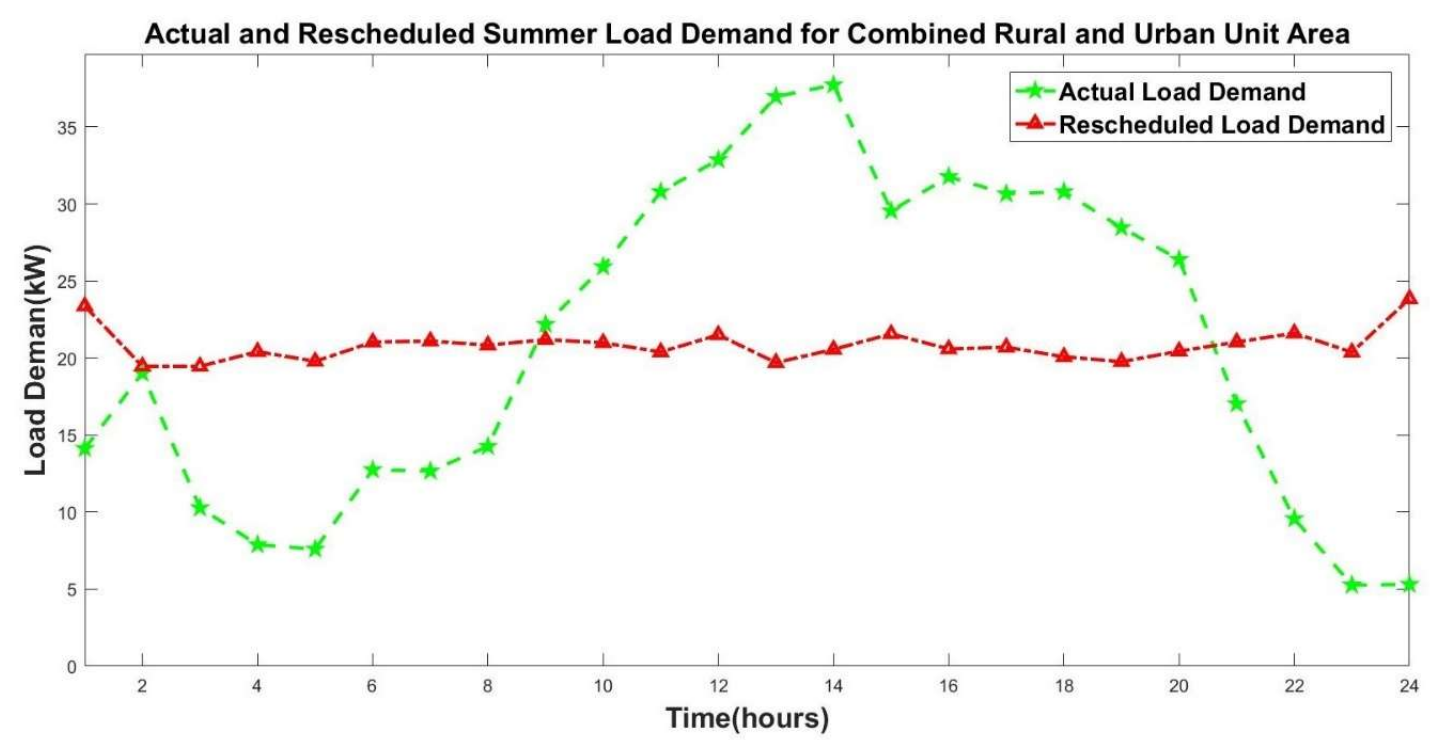

(a)

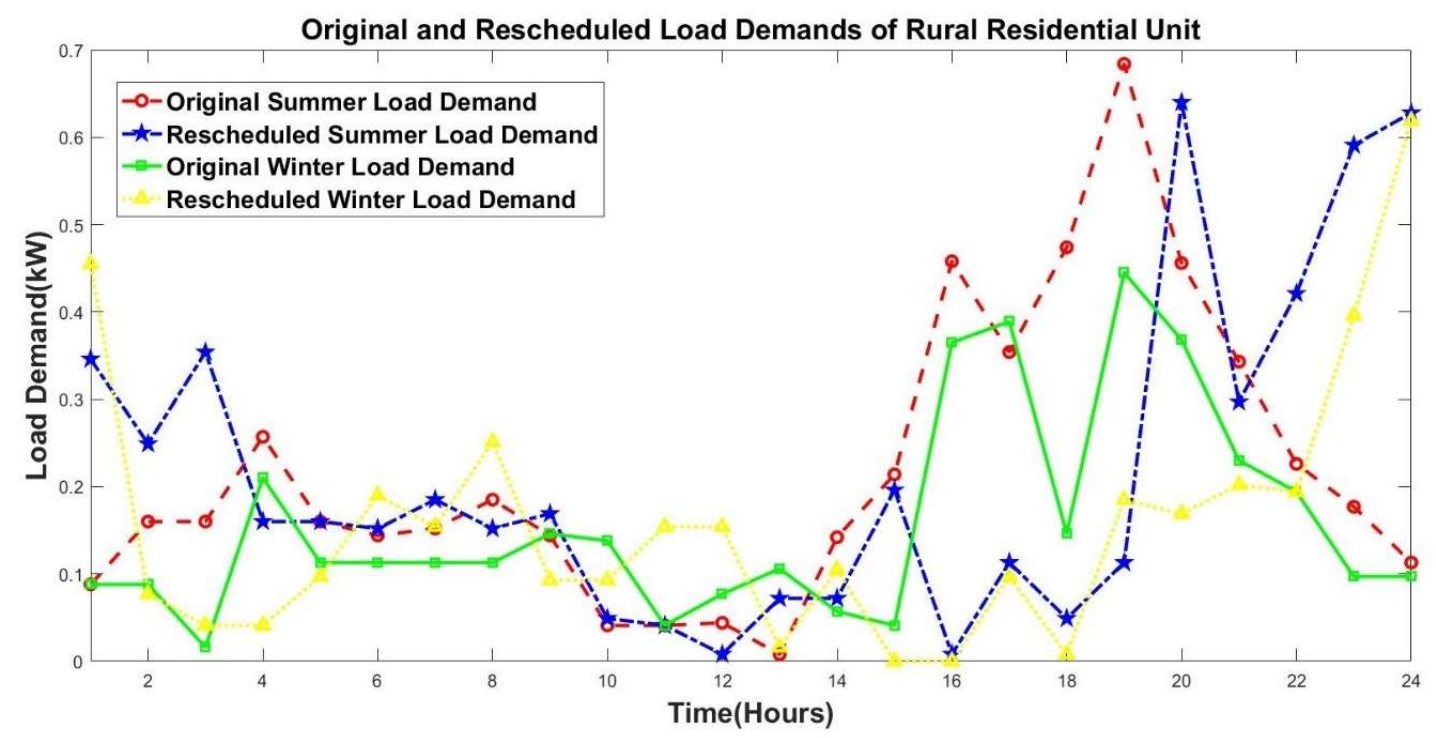

(b)

Figure 3. Actual and rescheduled load of combined area and rural unit (a) combined unit area load and (b) seasonal rural residential unit area load before and after scheduling

After rescheduling each load of every hour was passed through the fuzzy tool developed for tagging the loads to be either supplied by the renewable sources available or from the grid. The pseudocode of the developed fuzzy tool is given in Algorithm 1. The outputs providing the percentage and actual values of the rural residential hourly loads available for being supplied by renewbale in summer is shown in Figure 4(a) and Figure 4(b) respectively. The seasonal variation can be compared by observing the outputs providing the rural residential hourly loads available for being supplied by renewbale in winter shown in Figure 5(a) and Figure 5(b) respectively. This system provides us with a good insight into the characteristics of the load demand both region wise and consumer category wise. The major contribution of this work is providing a detailed model in which the loads are mapped to their probable supplies based on the region wise classification of urban, semi-urban and rural. The model is capable of identifying the type of region and consumer category to be addressed from the load demand profile of the region.

Bulletin of Electr Eng \& Inf, Vol. 11, No. 1, February 2022: 68-81 


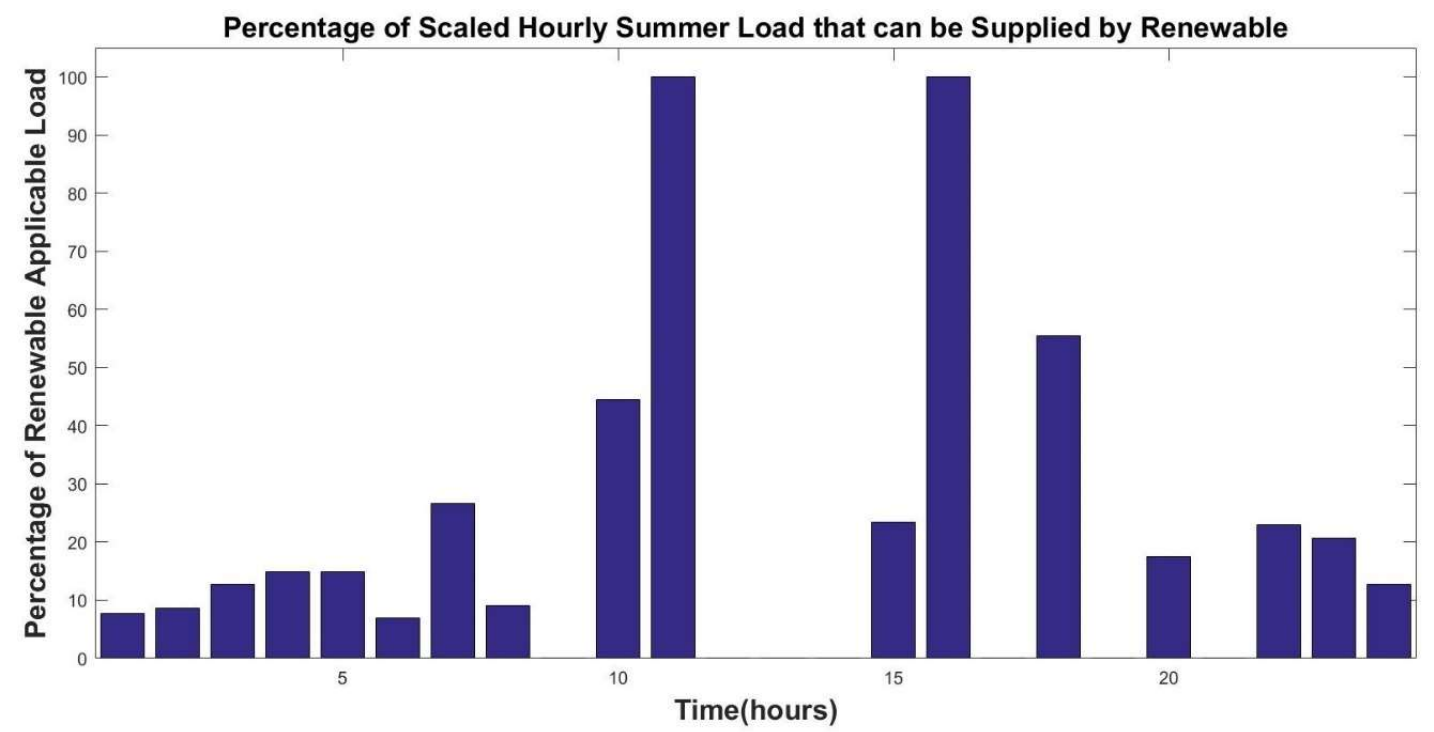

(a)

Figure 4. Percentage and actual rural residential loads available for renewable supply in summer

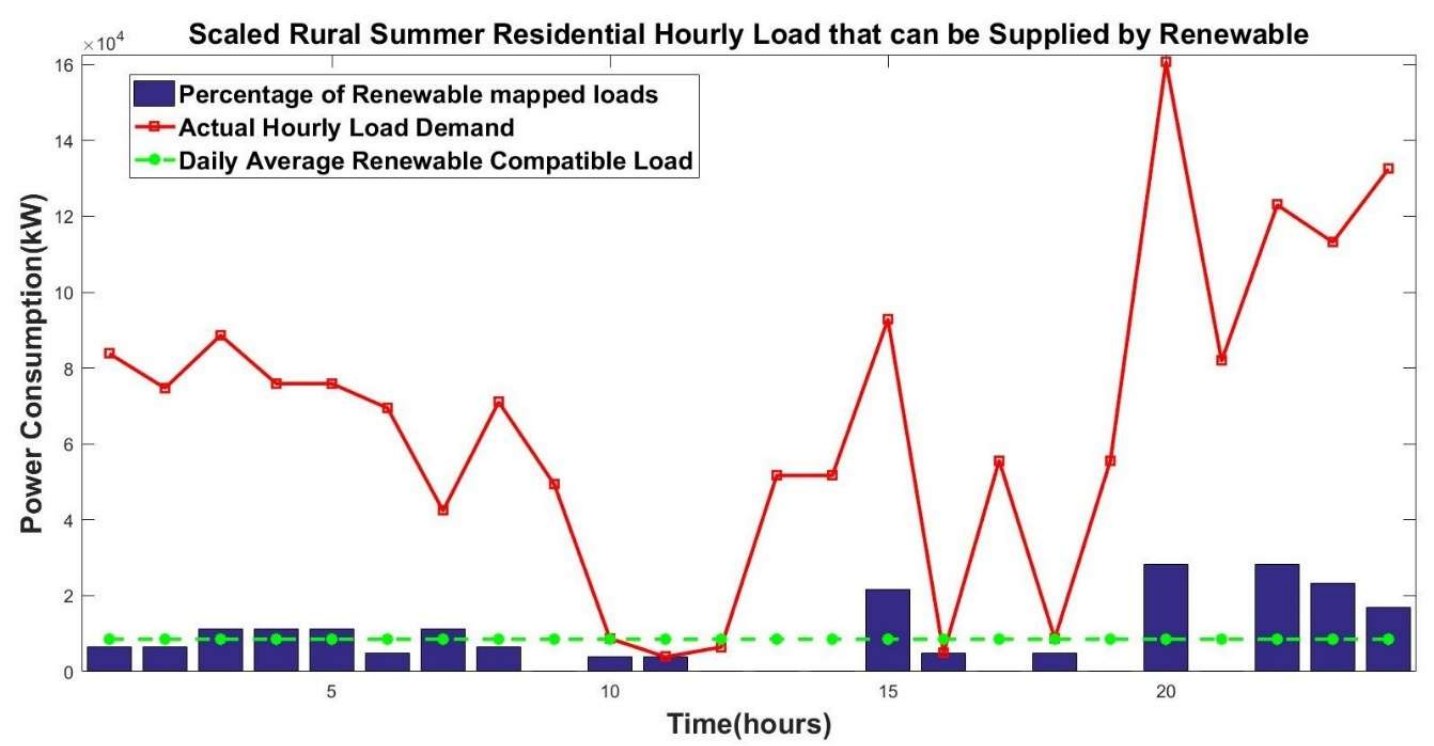

(b)

Figure 4. Percentage and actual rural residential loads available for renewable supply in summer (a) percentage of rural residential hourly load selected to be supplied by renewable and (b) actual value of rural residential rescheduled load to be supplied with renewable compared to total demand

This model can be utilised to develop a roadmap for the region wise development of renewable energy sources based on the growth of population and subsequent growth of load demand which depends upon the type of region under question and appliance ownership percentage in such regions. So, this model contributes in diversifying the load management system and tailor solutions to the needs of a particular region based upon the demographic and geographical characteristics of that region. It also provides a future roadmap of renewable energy development based on the load demand characteristic of the urban, semi-urban and rural regions which is very important for sustainable development. 


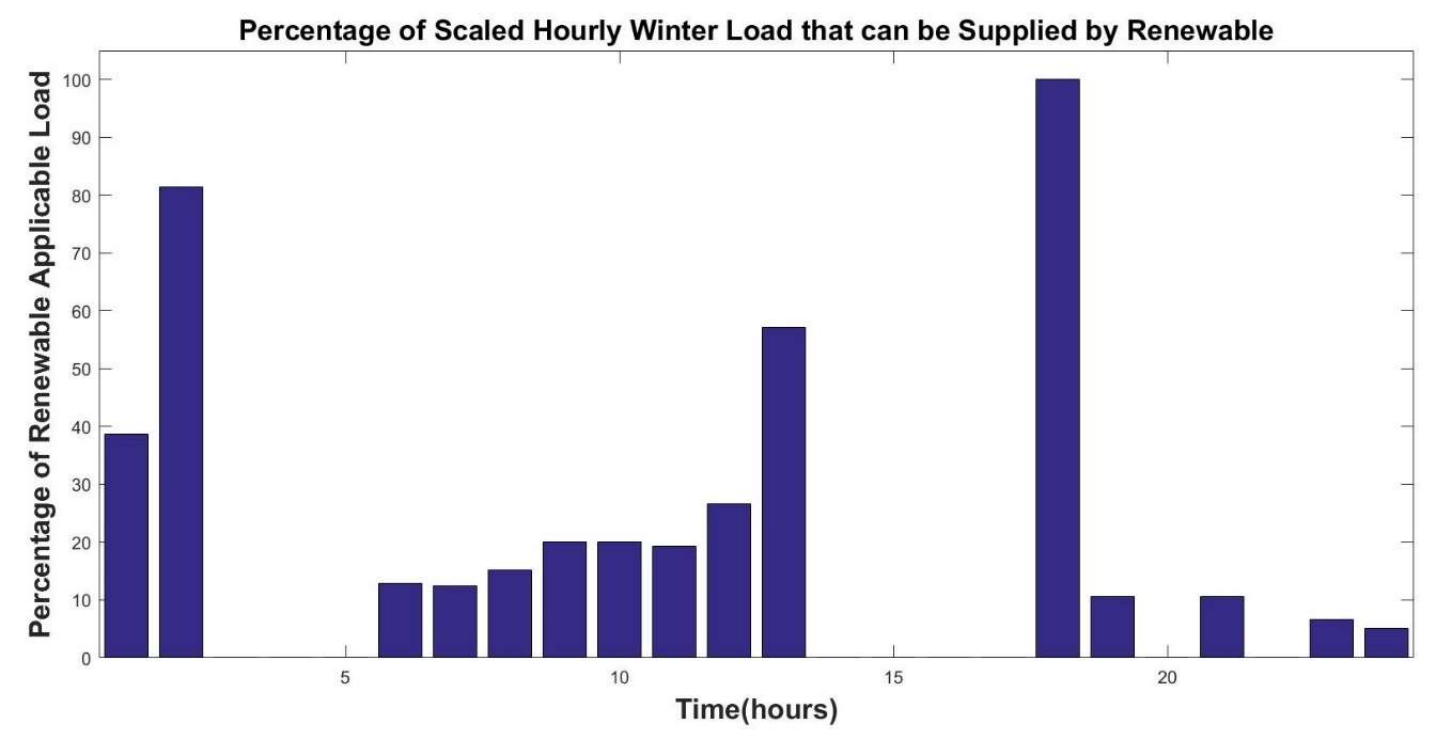

(a)

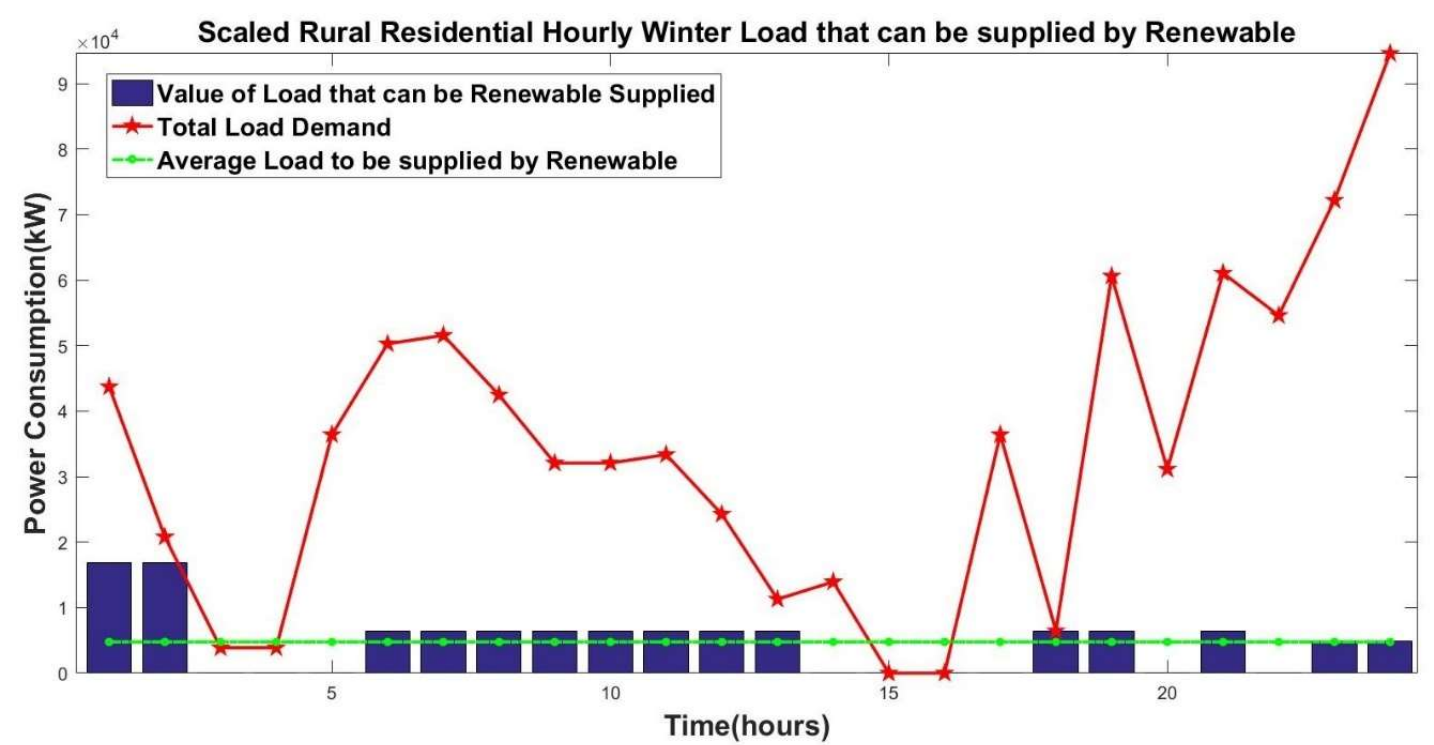

(b)

Figure 5. Percentage and actual rural residential loads available for renewable supply in winter (a) percentage of rural residential hourly load selected to be supplied by renewable and (b) actual value of rural residential rescheduled load to be supplied with renewable compared to total demand

The percentage of loads that are tagged for being supplied with renewable energy is found to be largely varying both region wise and consumer category wise. The percentage share of the loads of each region that can be supplied from renewable sources is shown in Table 4 . The load demand of the regions and the available renewable energy vary with changes in climatic factors. The demand supply variations have been shown in Table 5 referencing the values of which we can see a higher percentage of residential loads are selected for renewable supply compared to commercial loads. The reason being that residential units consume less power, are less critical and have more scheduling flexibility. For similar reasons, rural percentage of both the category of loads are higher than urban and semi urban. the values of urban and semi urban regions appear close to each other as the types of appliances used in these regions are nearly the same.

Bulletin of Electr Eng \& Inf, Vol. 11, No. 1, February 2022: 68-81 
Table 4. Percentage load selected for renewable supply per region and consumer category

\begin{tabular}{ccccc}
\hline Season & Consumer category & Urban & Semi Urban & Rural \\
\hline Summer & Residential & 4.79 & 10.42 & 29.1 \\
& Commercial & 14.615 & 14.721 & 12.88 \\
Winter & Residential & 6.09 & 7.1 & 31.26 \\
& Commercial & 14.13 & 14.3 & 17.81 \\
\hline
\end{tabular}

Table 5. Demand supply variation data

\begin{tabular}{cccccccc}
\hline \multirow{2}{*}{ Season } & \multirow{2}{*}{ Supply level } & \multicolumn{2}{c}{ Urban } & \multicolumn{2}{c}{ Semi urban } & \multicolumn{2}{c}{ Rural } \\
& & High demand & Low demand & High demand & Low demand & High demand & Low demand \\
\hline \multirow{2}{*}{ Summer } & High supply & 13.99 & 43.79 & 13.78 & 43.47 & 24.75 & 47.70 \\
& Low supply & 3.01 & 8.08 & 2.96 & 4.85 & 5.45 & 10.81 \\
\multirow{2}{*}{ Winter } & High supply & 7.16 & 19.38 & 6.50 & 19.45 & 7.16 & 20.96 \\
& Low supply & 1.47 & 4.35 & 1.35 & 4.36 & 9.32 & 19.61 \\
\hline
\end{tabular}

The lower values obtained during winter can be attributed to the following two reasons. The first is lesser renewable availability due to decreased solar intensity and shorter days. The second is the reduced use of space cooling appliances resulting in increased percentage share of heavier and more crtitical loads, which are less likely to be selected for renewable supply by the fuzzy tool, in the total load demand of the region. So, it is evident that the developed tool can distinctly distinguish between the different load profiles.

Also, the performance of the proposed method to suggest a renewable integration approach with distinctly different percentages for the different regions and consumer categories is also satisfactory. Summarising, it can be said that the proposed method is capable of providing a region wise load management solution distinctly capturing the diversity of the load demand characteristics of different regions and consumer categories.

\section{CONCLUSION}

The paper describes a new approach towards load management and renewable integration method based on regional approach considering the load demand characteristics of different consumer categories. The region classification tool and load selection for renewable supply has been developed using fuzzy logic and the rescheduling of loads using different parameters varying regionally for a better load factor has been done using PSO. The proposed solution assures to contain the entire range of regions and loads as obtained from data available from online repositories and surveys of different organisations. It is shown by the test results that the performance of the proposed method in recognising the type of region and consumer category from the load demand profile is satisfactory. Summarising, it can be said that the proposed method is capable of providing a region wise load management solution distinctly capturing the diversity of the load demand characteristics of different regions and consumer categories.

\section{REFERENCES}

[1] IEA, "World Energy Outlook 2019," Paris, 2019. [Online]. Available: https://www.iea.org/reports/world-energy-outlook-2019.

[2] M. M. Rahman and F. Begum, "Prospect of renewable energy resources in Bangladesh," International Journal of Power Electronics and Drive Systems (IJPEDS), vol. 12, no. 3, p. 1804, Sep. 2021, doi: 10.11591/ijpeds.v12.i3.pp1804-1812.

[3] Z. J. Paracha and P. Doulai, "Load Management Techniques And Methods In Electric Power System," in Proceedings of EMPD '98. 1998 International Conference on Energy Management and Power Delivery (Cat. No.98EX137), vol. 1, pp. 213-217, doi: 10.1109/EMPD.1998.705514.

[4] K. Deka, S. Mahapatra, P. K. Bordoloi, and B. Medhi, "Design and testing of a control system for Supply Side electrical load Management," in 2014 1st International Conference on Non Conventional Energy (ICONCE 2014), Jan. 2014, pp. 277-281, doi: 10.1109/ICONCE.2014.6808726.

[5] W.-N. Tan, M. T. Gan, and Z. L. Tan, "Optimization models for demand-side and supply-side scheduling in smart grids," in 2016 IEEE 16th International Conference on Environment and Electrical Engineering (EEEIC), Jun. 2016, pp. 1-5, doi: 10.1109/EEEIC.2016.7555476.

[6] R. C. G. Teive, "Demand side management for residential consumers by using direct control on the loads," in Fifth International Conference on Power System Management and Control, 2002, vol. 2002, pp. 233-237, doi: 10.1049/cp:20020040.

[7] A. Alwadie, "A Concise Review of Control Techniques for Reliable and Efficient Control of Induction Motor," International Journal of Power Electronics and Drive Systems (IJPEDS), vol. 9, no. 3, p. 1124, Sep. 2018, doi: 10.11591/ijpeds.v9.i3.pp11241139.

[8] M. A. Jubair et al., "Competitive analysis of single and multi-path routing protocols in mobile Ad-Hoc network," Indonesian Journal of Electrical Engineering and Computer Science, vol. 19, no. 1, p. 293, Jul. 2020, doi: 10.11591/ijeecs.v19.i1.pp293-300.

[9] T. O. Fahad and A. A. Ali, "Compressed fuzzy logic based multi-criteria AODV routing in VANET environment," International Journal of Electrical and Computer Engineering (IJECE), vol. 9, no. 1, p. 397, Feb. 2019, doi: 10.11591/ijece.v9i1.pp397-401.

[10] N. M. and Y. B. N., "Preemptive modelling towards classifying vulnerability of DDoS attack in SDN environment," International Journal of Electrical and Computer Engineering (IJECE), vol. 10, no. 2, p. 1599, Apr. 2020, doi: 10.11591/ijece.v10i2.pp1599-

Development of regional load management system based on rural, semi urban ... (Ayandeep Ganguly) 
1611.

[11] C. Fancy and M. Pushpalatha, "Traffic-aware adaptive server load balancing for software defined networks," International Journal of Electrical and Computer Engineering (IJECE), vol. 11, no. 3, p. 2211, Jun. 2021, doi: 10.11591/ijece.v11i3.pp22112218.

[12] J. Jiao, "Application and prospect of artificial intelligence in smart grid," IOP Conference Series: Earth and Environmental Science, vol. 510, no. 2, p. 022012, Jun. 2020, doi: 10.1088/1755-1315/510/2/022012.

[13] A. Jindal, M. Singh, and N. Kumar, "Consumption-Aware Data Analytical Demand Response Scheme for Peak Load Reduction in Smart Grid," IEEE Transactions on Industrial Electronics, vol. 65, no. 11, pp. 8993-9004, Nov. 2018, doi: 10.1109/TIE.2018.2813990.

[14] E. Jarmouni, A. Mouhsen, M. Lamhammedi, and H. Ouldzira, "Integration of artificial neural networks for multi-source energy management in a smart grid," International Journal of Power Electronics and Drive Systems (IJPEDS), vol. 12, no. 3, p. 1919, Sep. 2021, doi: 10.11591/ijpeds.v12.i3.pp1919-1927.

[15] S. M. Hameed, H. K. AL-Qaysi, A. S. Kaittan, and M. H. Ali, "Evaluation of electrical load estimation in Diyala governorate (Baaquba city) based on fuzzy inference system," International Journal of Electrical and Computer Engineering (IJECE), vol. 11, no. 5, p. 3757, Oct. 2021, doi: 10.11591/ijece.v11i5.pp3757-3762.

[16] K. N, A. K. Parvathy, A. Rajagopalan, and S. Baskar, "A review of optimization techniques applied to solve unit commitment problem in microgrid," Indonesian Journal of Electrical Engineering and Computer Science, vol. 15, no. 3, p. 1161, Sep. 2019, doi: 10.11591/ijeecs.v15.i3.pp1161-1169.

[17] A. A. R. Altahir and M. M. Marei, "An optimal allocation of UPFC and transient stability improvement of an electrical power system: IEEE-30 buses," International Journal of Electrical and Computer Engineering (IJECE), vol. 11, no. 6, p. 4698, Dec. 2021, doi: 10.11591/ijece.v11i6.pp4698-4707.

[18] A. K. Kirgizov, S. A. Dmitriev, M. K. Safaraliev, D. A. Pavlyuchenko, A. H. Ghulomzoda, and J. S. Ahyoev, "Expert system application for reactive power compensation in isolated electric power systems," International Journal of Electrical and Computer Engineering (IJECE), vol. 11, no. 5, p. 3682, Oct. 2021, doi: 10.11591/ijece.v11i5.pp3682-3691.

[19] A. T. Nguyen, N. T. Le, A. H. Quyen, B. T. T. Phan, T. P. Trieu, and T. D. Hua, "Application of AHP algorithm on power distribution of load shedding in island microgrid," International Journal of Electrical and Computer Engineering (IJECE), vol. 11, no. 2, p. 1011, Apr. 2021, doi: 10.11591/ijece.v11i2.pp1011-1021.

[20] K. Mahmud, M. J. Hossain, and G. E. Town, "Peak-Load Reduction by Coordinated Response of Photovoltaics, Battery Storage, and Electric Vehicles," IEEE Access, vol. 6, pp. 29353-29365, 2018, doi: 10.1109/ACCESS.2018.2837144.

[21] K. Mahmud, M. J. Hossain, and J. Ravishankar, "Peak-Load Management in Commercial Systems With Electric Vehicles," IEEE Systems Journal, vol. 13, no. 2, pp. 1872-1882, Jun. 2019, doi: 10.1109/JSYST.2018.2850887.

[22] N. Javaid, G. Hafeez, S. Iqbal, N. Alrajeh, M. S. Alabed, and M. Guizani, "Energy Efficient Integration of Renewable Energy Sources in the Smart Grid for Demand Side Management," IEEE Access, vol. 6, pp. 77077-77096, 2018, doi: 10.1109/ACCESS.2018.2866461.

[23] K. Parvin, M. A. Hannan, A. Q. Al-Shetwi, P. J. Ker, M. F. Roslan, and T. M. I. Mahlia, "Fuzzy Based Particle Swarm Optimization for Modeling Home Appliances Towards Energy Saving and Cost Reduction Under Demand Response Consideration," IEEE Access, vol. 8, pp. 210784-210799, 2020, doi: 10.1109/ACCESS.2020.3039965.

[24] A. Sumaiti, S. Konda, L. Panwar, V. Gupta, R. Kumar, and B. Panigrahi, "Aggregated Demand Response Scheduling in Competitive Market Considering Load behavior through Fuzzy Intelligence," IEEE Transactions on Industry Applications, pp. 11, 2020, doi: 10.1109/TIA.2020.2988853.

[25] H. Gong, V. Rallabandi, M. L. McIntyre, E. Hossain, and D. M. Ionel, "Peak Reduction and Long Term Load Forecasting for Large Residential Communities Including Smart Homes With Energy Storage," IEEE Access, vol. 9, pp. 19345-19355, 2021, doi: 10.1109/ACCESS.2021.3052994.

[26] C. Wang, S. Chen, S. Mei, R. Chen, and H. Yu, "Optimal Scheduling for Integrated Energy System Considering Scheduling Elasticity of Electric and Thermal Loads," IEEE Access, vol. 8, pp. 202933-202945, 2020, doi: 10.1109/ACCESS.2020.3035585.

[27] O. I. Oluwasuji, O. Malik, J. Zhang, and S. D. Ramchurn, "Solving the fair electric load shedding problem in developing countries," Autonomous Agents and Multi-Agent Systems, vol. 34, no. 1, p. 12, Apr. 2020, doi: 10.1007/s10458-019-09428-8.

[28] J. Tu, M. Zhou, H. Cui, and F. Li, "An Equivalent Aggregated Model of Large-Scale Flexible Loads for Load Scheduling," IEEE Access, vol. 7, pp. 143431-143444, 2019, doi: 10.1109/ACCESS.2019.2944233.

[29] X. Ran and S. Leng, "Enhanced Robust Index Model for Load Scheduling of a Home Energy Local Network With a Load Shifting Strategy," IEEE Access, vol. 7, pp. 19943-19953, 2019, doi: 10.1109/ACCESS.2018.2889762.

[30] G. J. Prinsloo, "Scoping exercise to determine load profile archetype reference shapes for solar co-generation models in isolated off-grid rural African villages," Journal of Energy in Southern Africa, vol. 27, no. 3, p. 11, Nov. 2016, doi: 10.17159/24133051/2016/v27i3a1375.

[31] F. Pereira, P. Faria, and Z. Vale, "Definition of distinct consumer modelling approaches for the participation in Demand Response programs considering distributed generation," in 2015 IEEE PES Innovative Smart Grid Technologies Latin America (ISGT LATAM), Oct. 2015, pp. 608-613, doi: 10.1109/ISGT-LA.2015.7381224.

[32] S. M. Faresse, M. Assini, and A. Saad, "Hybrid energy storage system optimal sizing for urban electrical bus regarding battery thermal behavior," International Journal of Electrical and Computer Engineering (IJECE), vol. 10, no. 3, p. 2894, Jun. 2020, doi: 10.11591/ijece.v10i3.pp2894-2911.

[33] M. A. M. Shaaban, H. Zeynal, and K. Nor, "MILP-Based Short-Term Thermal Unit Commitment and Hydrothermal Scheduling Including Cascaded Reservoirs and Fuel Constraints," International Journal of Electrical and Computer Engineering (IJECE), vol. 9, no. 4, p. 2732, Aug. 2019, doi: 10.11591/ijece.v9i4.pp2732-2742.

[34] J. Sankar V.C. et al., "Management of Unprioritized Loads in an Islanded Microgrid: Algorithms for Scheduling of Historic Load Data and Real-Time Load Management," in 2019 Innovations in Power and Advanced Computing Technologies (i-PACT), Mar. 2019, pp. 1-5, doi: 10.1109/i-PACT44901.2019.8960207.

[35] R. B. M, C. V. Kumar, and R. Sreekanth, "Optimal volt/var control of distribution system using MOPSO," Indonesian Journal of Electrical Engineering and Computer Science, vol. 16, no. 3, p. 1088, Dec. 2019, doi: 10.11591/ijeecs.v16.i3.pp1088-1095.

[36] C. Mahmoudi, F. Aymen, and S. Lassaad, "Smart database concept for Power Management in an electrical vehicle," International Journal of Power Electronics and Drive Systems (IJPEDS), vol. 10, no. 1, p. 160, Mar. 2019, doi: 10.11591/ijpeds.v10.i1.pp160169.

[37] L. Ciabattoni, M. Grisostomi, G. Ippoliti, and S. Longhi, "A Fuzzy Logic tool for household electrical consumption modeling," in IECON 2013 - 39th Annual Conference of the IEEE Industrial Electronics Society, Nov. 2013, pp. 8022-8027, doi: 10.1109/IECON.2013.6700474.

Bulletin of Electr Eng \& Inf, Vol. 11, No. 1, February 2022: 68-81 
[38] A. Kadri and F. Mohammadi, "ANN Daily Peak Forecast for Peak Demand Charges Management," in 2020 IEEE Canadian Conference on Electrical and Computer Engineering (CCECE), Aug. 2020, pp. 1-5, doi: 10.1109/CCECE47787.2020.9255778.

[39] A. Almalaq and G. Edwards, "Comparison of Recursive and Non-Recursive ANNs in Energy Consumption Forecasting in Buildings," in 2019 IEEE Green Technologies Conference(GreenTech), Apr. 2019, pp. 1-5, doi: 10.1109/GreenTech.2019.8767130.

[40] A. Garg, J. Maheshwari, and J. Upadhyay, "Load Research for Residential and Commercial Establishments in Gujrat," IIMA Institutional Repository, 2010.

[41] The Rockefeller Foundation, "Rural Electrification in India: Customer Behaviour and Demand," 2019. [Online]. Available: https://www.rockefellerfoundation.org/wp-content/uploads/Rural-Electrification-in-India-Customer-Behaviour-and-Demand.pdf.

\section{BIOGRAPHIES OF AUTHORS}

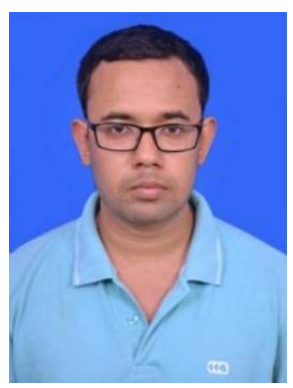

Ayandeep Ganguly (D) SC P is an Assistant Professor at Haldia Institute of Technology with Master of Technology from Calcutta University (2012). He obtained Bachelor Degree in Electrical Engineering from West Bengal University of Technology in 2010. His researches are in fields of power system, renewable energy, demand side management, artificial intelligence application in power systems. He can be contacted at email: gangulyayandeep@hithaldia.in.

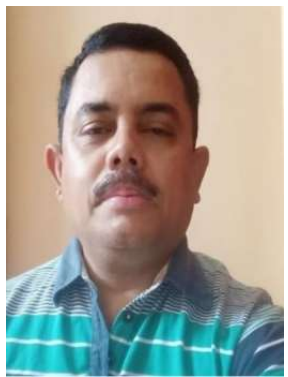

Dr. Arindam Kumar Sil (D) R SC P is an Associate Professor at Jadavpur University with Doctor of Philosophy in Electrical Engineering from Jadavpur University, India. He obtained Master of Engineering in Power Engineering from Jadavpur University, India and B.E degree in Electrical and Electronics Engineering from Karnataka University, Dharwad, India. His researches are in fields of power system, renewable energy, demand side management, artificial intelligence application in power systems. He can be contacted at email: ak_sil@yahoo.co.in. 